\title{
PERANCANGAN WEB SERIES FILM DOKUMENTER SEBAGAI MEDIA REVITALISASI KOPI JAWA DI NGAWONGGO, KALIANGKRIK, MAGELANG, JAWA TENGAH
}

\author{
Widhi Nugroho ${ }^{1)}$, I Putu Suhada ${ }^{2)}$ \\ Latief Rahman Hakim ${ }^{3)}$, Pius Rino Pungkiawan ${ }^{4)}$ \\ Program Studi S-1 Televisi dan Film, Fakultas Seni Rupa dan Desain \\ Institut Seni Indonesia Surakarta \\ E-mail: widhinugroho1980@gmail.com \\ Program Studi S-1 Televisi dan Film, Fakultas Seni Rupa dan Desain \\ Institut Seni Indonesia Surakarta \\ E-mail:ipsa@gmail.com \\ ${ }^{3}$ Jurusan Televisi, Fakultas Seni Media Rekam \\ Institut Seni Indonesia Yogyakarta \\ Jalan Parangtritis Km 6,5 Sewon, Yogyakarta \\ E-mail: latiefrh@gmail.com \\ ${ }^{4}$ Jurusan Televisi, Fakultas Seni Media Rekam \\ Institut Seni Indonesia Yogyakarta \\ Jalan Parangtritis Km 6,5 Sewon, Yogyakarta \\ E-mail: piusrinop@gmail.com
}

\begin{abstract}
ABSTRAK
Revitalisasi adalah proses, cara, perbuatan menghidupkan atau menggiatkan kembali. Dalam konteks ini, revitalisasi pertanian mengandung arti sebagai kesadaran untuk menempatkan kembali arti penting sektor pertanian secara proporsional dan kontekstual, dalam arti menyegarkan kembali vitalitas, memberdayakan kemampuan, dan meningkatkan kinerja pertanian dalam pembangunan dengan tanpa mengabaikan sektor lain. Pemerintah mewujudkan hal ini dengan mendorong sektor pertanian kopi sebagai salah satu penguat daya saing Indonesia di pasar internasional. Berbicara kopi di Indonesia tidak akan pernah bisa lepas dari sejarah kopi di Jawa. Kopi Jawa (Java coffee) yang kemudian sering disebut ini merupakan salah satu cikal bakal dikenalnya Indonesia sebagai salah satu negara terbesar penghasil kopi di dunia. Berdasar uraian tersebut, web series dipilih sebagai media ungkap dalam upaya peran serta memajukan para petani kopi menuju kemandirian serta kedaulatan ekonomi menuju desa berdaya melalui potensi masyarakat desa. Metode deskriptif kualitatif digunakan dalam perancangan web series ini. Hal ini dilakukan guna mendapatkan datadata penting secara substantif dalam penyusunan unsur naratif (cerita) berkenaan dengan “Kopi Kaliangkrik di Ngawonggo, Kaliangkrik, Magelang, Jawa Tengah". Perancangan web series ini bertujuan mewujudkan film dokumenter sebagai salah satu media revitalisasi kopi, terutama kopi Jawa. Hasil yang dicapai dalam perancangan web series ini adalah peran serta media sebagai salah satu sarana dalam upaya peningkatan nilai tambah (added value) produk pertanian kopi di Indonesia.
\end{abstract}

Kata kunci: web series, film, dokumenter, revitalisasi, kopi

\section{ABSTRACT}

Web Series Design of Documentary Film as Revitalization Media of Java Coffee in Ngawonggo, Kaliangkrik, Magelang, Central Java. Revitalization is the process, method, act of reviving or activating something. In this context, agricultural revitalization implies awareness to place proportional and contextual importance in the agricultural sector, in the sense of refreshing vitality, empowering capabilities, and improving agricultural performance 
in its development without ignoring other sectors. The government actualizes it by encouraging the coffee agriculture sector as one of the mainstays of Indonesia's competitiveness in the international market. Conferring about coffee in Indonesia can never be separated from the history of coffee in Java. Java coffee which is then often referred to is one of the forerunners of the recognition of Indonesia as one of the largest coffee producing countries in the world. Based on the aforementioned description, the web series was chosen as the media to reveal the effort of participating in advancing coffee farmers towards their own independence and economic sovereignty towards empowered villages through the potential of rural communities. Qualitative descriptive methods are used in designing this web series. The methods were applied in order to obtain important data substantively in the compilation of narrative elements (stories) regarding the Kaliangkrik Coffee in Ngawonggo Village, Kaliangkrik District, Magelang Regency, Central Java Province. The web series design aims to realize documentary films as one of the coffee revitalization media, especially Java coffee. The results achieved in designing this web series are the role of the media as one of the instruments in increasing the added value of coffee agricultural products in Indonesia.

Keywords: web series, documentary, film, revitalization, coffee

\section{PENDAHULUAN}

Berbicara kopi di Indonesia tidak akan pernah bisa terlepas dari sejarah kopi di Jawa. Kopi jawa yang kemudian sering disebut ini merupakan salah satu cikal bakal dikenalnya Indonesia sebagai salah satu negara terbesar penghasil kopi di dunia. Menurut buku All About Coffee yang ditulis oleh William Harrison Ukers (Ukers, 1922), kopi kali pertama didatangkan ke Batavia (Jakarta) oleh Belanda pada tahun 1696. Jenis kopi yang didatangkan dan ditanam kala itu ialah jenis arabika. Kebun tanaman kopi arabika meliputi daerah Bidaracina, Jatinegara, Palmerah, dan Kampung Melayu di Batavia hingga kemudian menyebar ke daerah Jawa Barat, Jawa Tengah, dan Jawa Timur.

Beberapa tahun kemudian, tepatnya pada tahun 1711 pemerintah Belanda melalui Vereenigde Oostindische Compagnie (VOC) melakukan ekspor kali kali pertama kopi jawa ke kota Amsterdam (Belanda) di sebuah acara lelang kopi tingkat dunia. Asal kopi jawa pada saat itu dari Buitenzorg (Bogor), Preanger (Priangan/Bandung), Cheribon (Cirebon), Kadoe (Karesidenan Kedu), Semarang, dan Malang. Para ahli kopi waktu itu terkagumkagum dengan cita rasa kopi jawa yang mampu menandingi cita rasa kopi yang berasal dari daratan Amerika Selatan, seperti Brazil dan Kolombia. Harga kopi jawa terbilang cukup menjanjikan dengan mencatat rekor penjualan sebesar 51,7 stuviers atau 6,47 gulden per kilogram. Pada saat itu, tibalah era penanam kopi secara besar-besaran di bumi Indonesia.

Sejak saat itu, kopi jawa "naik pamor" menjadi primadona komoditas pertanian oleh VOC. Mulai tahun 1725 VOC memonopoli perdagangan kopi di Indonesia. Terlebih, dengan sistem tanam paksa yang digagas oleh Gubernur Johanes Graaf van Den Bosch pada tahun 1831-1877. Dari hasil komoditas kopi ini pemerintah Belanda mampu membayar utang negara sebesar 12 juta gulden kepada pihak lain. Hal ini yang membuat rakyat Indonesia, khususnya pemilik lahan dan petani jatuh dalam penjajahan dalam bentuk "baru". Mereka dipaksa untuk menanam kopi dalam jumlah besar dengan harga yang sudah ditentukan oleh VOC pada saat panen.

Lebih lanjut berdasar wawancara yang dilakukan dengan Surip Mawardi (Pusat Penelitian Kopi dan Kakao Indonesia) pada tahun 1875, kopi jawa jenis arabika terserang hama karat daun yang mengakibatkan hasil produksi 
menurun drastis. Kopi jenis liberika kemudian didatangkan guna mengganti dan menggenjot produksi kopi di Pulau Jawa. Akan tetapi, kondisi ini tidak bisa bertahan lama karena kondisi tanah dan iklim yang tidak sesuai. Pada tahun 1900-an kopi jenis robusta diperkenalkan, dan pada saat itulah "robustanisasi" kopi jawa dimulai. Untuk itu, mengenalkan kembali kopi jawa melalui media web series (film dokumenter) kepada masyarakat luas perlu dilakukan sebagai salah satu bentuk revitalisasi kopi jawa melalui media.

Revitalisasi merujuk pada Kamus Besar Bahasa Indonesia bermakna proses, cara, perbuatan menghidupkan, atau menggiatkan kembali. Dalam konteks ini, seperti yang disarikan melalui data pemerintah, revitalisasi pertanian mengandung arti sebagai kesadaran untuk menempatkan kembali arti penting sektor pertanian secara proporsional dan kontekstual, dalam arti menyegarkan kembali vitalitas, memberdayakan kemampuan dan meningkatkan kinerja pertanian dalam pembangunan dengan tanpa mengabaikan sektor lainnya (Direktorat Evaluasi Kinerja Pembangunan Sektoral Kementerian PPN/Bapenas, 2010). Lebih lanjut dalam kutipan dapat dijelaskan sebagai berikut.

Presiden Joko Widodo (Jokowi) secara gamblang mengungkapkan keinginannya membawa kopi Indonesia ke tingkat dunia. Pak Presiden menginginkan adanya perbaikan posisi Indonesia sebagai produsen kopi dunia. Seperti kita tahu, saat ini Indonesia berada di peringkat keempat negara penghasil kopi di dunia. Pak Presiden ingin Indonesia naik ke peringkat ketiga, lalu kedua, atau bahkan jadi nomor satu. Tapi ada tantangan tambahan untuk mencapai hal itu. Kita harus melakukan apa yang namanya creating value added. Itu artinya, Indonesia tidak hanya sekadar menjadi produsen biji kopi. Tapi juga sebagai pemasar merek dan kedai kopi ke seluruh dunia. Ini akan memberi nilai tambah Indonesia sebagai produsen kopi secara internasional (Triawan Munaf-Kepala Badan Kreatif Indonesia, November 2017)

Seperti yang telah disebutkan dalam kutipan tersebut, meninjau kembali mengenai komoditas pertanian, sebagai salah satu pendukung kinerja sektor pertanian, kopi merupakan salah satu penyumbang devisa bagi negara, bahkan pada saat masa penjajahan Belanda. Merunut sejarah, wilayah Kadoe (Kedu/Karesidenan Kedu) merupakan salah satu penghasil kopi jawa saat itu (Ukers, 1922). Ini merupakan bukti nyata bahwa kopi arabika yang berasal dari daerah Kedu (sekarang Magelang) pernah menjadi salah satu "idola" pasar kopi dunia. Sejarah telah berlalu dan tidak akan terulang. Akan tetapi, berbeda dengan cara pandang seorang Rinto, pemuda tekun dan ulet yang gigih bercita-cita mengembalikan lagi pamor kopi arabika jawa ke pentas dunia. Pemuda asal Pengkol, Ngawonggo, Kaliangkrik, Magelang, Jawa Tengah ini melalui Kelompok Tani Mekar Lestari berupaya membudidayakan kopi arabika jawa yang mampu "berbicara" kepada dunia.

Dari beberapa uraian tersebut dapat ditarik sebuah rumusan permasalahan yang akan menjadi fokus objek kajian perancangan web series ini, yakni: (a) bagaimana mewujudkan karya web series film dokumenter yang bersifat informatif, membagikan pengetahuan baru kepada khalayak yang berguna sebagai media revitalisasi kopi jawa menuju desa berdaya melalui potensi masyarakat desa, industri kreatif pertanian dan pengolahan kopi di Jawa Tengah dan (b) bagaimana pendistribusian film dokumenter ini agar dapat diakses oleh publik atau khalayak luas melalui tayangan web series pada situs YouTube beserta jejaringnya melalui media internet. 
Sesuai dengan rumusan masalah tersebut, tujuan dan manfaat perancangan web series ini adalah: (a) mendeskripsikan proses kerja kreatif dalam perwujudan karya film dokumenter yang mengiformasikan revitalisasi kopi jawa menuju desa berdaya melalui potensi masyarakat desa, industri kreatif pertanian dan pengolahan kopi sebagai sarana advokasi dalam upaya merevitalisasi kopi jawa di Jawa Tengah (dipublikasikan melalui jurnal dan HAKI) dan (b) mendeskripsikan pendistribusian film dokumenter serial ini agar dapat diakses oleh publik atau khalayak luas melalui tayangan web series pada situs YouTube beserta jejaringnya media internet.

Adapun urgensi perancangan web series adalah: (a) bagi perancang/peneliti dapat bermanfaat dalam melihat bahwa kelompok masyarakat yang bergerak pada sektor pertanian dan industri kreatif khususnya kopi sebagai subjek penciptaan karya film dokumenter juga dapat dijadikan sebagai objek kajian dalam penguatan penciptaan karya berbasis riset. Terlebih, ikut berperan aktif dalam pembuatan karya media revitalisasi kopi jawa; (b) bagi keilmuan, perancangan web series ini dapat digunakan sebagai model penciptaan bagi para pembuat film dokumenter untuk berkarya melalui medium film, terlebih di lembaga pendidikan yang mempunyai program studi televisi dan film melalui mata kuliah seperti riset kreatif, riset dokumenter, dan penyutradaraan dokumenter. Di samping itu, proses kreatif penciptaan karya film dokumenter ini secara ilmiah dipublikasikan melalui jurnal dan HAKI; (c) bagi umum, menjadi model alternatif pembuatan karya film dokumenter serial dengan media pancar berupa internet (tayangan web series di YouTube) yang lebih independen dalam pendistribusian sehingga dapat merangsang dan menumbuhkankembangkan kemandirian dalam berkarya serta apresiasi karya.
Target perancangan web series ini adalah: (a) menempatkan media film dokumenter sebagai salah satu sarana pembelajaran bagi khalayak, khususnya petani kopi sebagai apresiator; (b) penelitian artistik ini dapat digunakan sebagai model penciptaan karya bagi para pembuat film dokumenter melalui pemanfaatan media internet (web series di situs YouTube); (c) pengayaan bahan ajar untuk mata kuliah riset kreatif, riset dokumenter, dan penyutradaraan dokumenter; (d) publikasi ilmiah berupa jurnal ilmiah nasional terakreditasi; (e) dan HAKI atas karya perancangan web series film dokumenter.

\section{TINJAUAN PUSTAKA DAN KARYA}

Beberapa buku dan jurnal ataupun tulisan yang publikasikan secara on-line di internet digunakan sebagai acuan dalam pembuatan video dokumenter profil ini. Buku-buku ataupun jurnal/tulisan tersebut merupakan satu rangkaian pengetahuan yang menjadi landasan dalam proses penelitian kekaryaan ini. Berikut adalah beberapa sumber pengetahuan yang akan digunakan sebagai landasan perancangan karya web series ini. Buku yang berjudul All About Coffee yang ditulis oleh Ukers (1922) banyak mengupas seluk beluk tentang kopi. Sejarah kopi dunia hingga masuk ke Indonesia dikupas secara cermat di sini berdasar periodisasi. Dalam buku ini dijelaskan pula karakteristik kopi yang berasal dari berbagai belahan dunia, termasuk Indonesia salah satunya. Data-data numerik mengenai produksi kopi dan arsip foto banyak ditampilkan dalam buku ini sehingga memberi gambaran konkret posisi kopi jawa di pasar dunia pada saat itu.

Buku The Road to Java Coffee yang ditulis oleh Prawoto Indarto (Prawoto, 2013) merupakan buku hasil dari rangkaian panjang 
perjalanan menemukan sejarah kopi, khususnya kopi di Tanah Jawa. Buku ini memberi ulasan sejarah kopi dengan sudut pandang etimologis. Data-data spesifik mengenai rentetan peristiwa dan perjalanan kopi hingga sampai ke Nusantara dijelaskan secara akurat dalam buku ini.

Rosenthal (1990) (pembuat film dokumenter) dalam bukunya Writing, Directing, Producing Documentary Films dan Writing, Directing, Producing Documentary Films and Videos (Revised Edition) terbitan Focal Press Boston Amerika memberi banyak kupasan tentang langkah-langkah/tahapan dalam merealisasikan sebuah ide film dokumenter hingga ke tahap produksi (realisasi) film dokumenter. Buku tersebut memberikan petunjuk yang dapat dipahami, disertai contohcontoh kasus sehingga pembaca dapat belajar memahami metode-metode pembuatan sebuah film dokumenter dari tahapan ide/gagasan, penulisan cerita, penyutradaraan dan produksi sebuah film dokumenter.

Buku Developing Story Ideas and Directing The Documentary karya Rabiger (1992) terbitan Focal Press ini hampir mempunyai kesamaan dengan buku karya Alan Rosenthal, mengetengahkan contoh-contoh kasus sebagai dasar penulisan naskah cerita. Akan tetapi, dalam buku tersebut pembaca akan lebih memahami kajian cerita dalam sebuah karya dokumenter. Rabiger menjelaskan lebih lanjut bagaimana cara menentukan sudut pandang sebuah cerita, cara bertutur hingga kurva dramatik dalam penyampaian isi dari sebuah film dokumenter.

Fred Wibowo dalam bukunya Dasar-

Dasar Produksi Program Televisi terbitan Grasindo Jakarta dan Jurnalistik Televisi Mutakhir karya Morissan terbitan Ramdina Prakarsa Tangerang menjadi acuan untuk lebih memahami prinsip-prinsip dasar jurnalistik. Wibowo (1997) berujar bahwa dokumenter dapat juga meminjam beberapa prinsip jurnalistik dalam proses pembuatannya. Dari buku-buku tersebut dapat dipelajari bagaimana cara melakukan riset, pengembangan ide, hingga proses pelaksanaan produksi yang erat kaitannya dengan konsep serta teknik penyutradaraan, terlebih dalam konteks dokumenter.

Selanjutnya, buku Television Production (Third Edition) karya Alan Wurtzel dan Stephen R Acker (Wurtzel \& Acker R., 1983) terbitan McGraw-Hill Inc menjelaskan fungsi dan teknis operasional dalam dunia pertelevisian. Dalam hal ini fungsi dan teknis director (pengarah acara) dalam sebuah produksi televisi akan dibahasa secara terperinci.

Buku Produksi Acara Televisi terbitan Duta Wacana University Press karya Subroto (1994) menjadi rujukan dalam mempelajari dasar-dasar produksi dalam dunia pertelevisian. Buku ini merupakan salah satu "versi bahasa Indonesia" dari buku Television Production (Third Edition) karya Wurtzel \& Acker (1983) terbitan McGraw-Hill Inc.

Dokumenter adalah sebuah karya yang menampilkan realita apa adanya (berdasarkan fakta) tanpa unsur rekayasa. German G. Mintapradja dalam sebuah artikel tentang film dokumenter majalah Behind The Screen edisi November 2005 berujar bahwa dalam dokumenter soal setting pun juga harus tanpa dramatisasi, bukan rekayasa yang dibuat di studio. Bahkan, sampai proses editing pun unsur dramatisasi itu tidak boleh muncul. Masih berdasar majalah Behind The Screen, sekarang seiring dengan perkembangan dunia film, dokumenter memunculkan varian-varian baru seperti docudrama, hybrid documentary dan 
newspack. Docudrama adalah dokumenter yang sudah dicampuriunsurfiksididalamnya. Program Anak Seribu Pulau merupakan salah satu contoh bentuk dari docudrama. Hybrid documentary adalah dokumenter yang berakulturasi dengan seni desain grafis dan animasi. Newspack adalah dokumenter yang mengupas sisi lain dari sebuah berita yang sedang hangat dibahas sehingga ada informasi tambahan untuk penonton.

Perkembangan bentuk dokumenter ini merupakan suatu hal yang sangat positif. Nan T Achnas dan IGP Wiranegara (pelaku dan pengamat film dokumenter), masih dalam artikel yang sama dalam majalah Behind The Screen, berpendapat dengan penggabungan dari medium-medium (varian) yang ada tersebut karya dokumenter justru akan lebih menarik. Akulturasi dari berbagai medium-medium itu membuat karya dokumenter semakin kaya dan entertaining. Sebagai contoh sekarang ada film dokumenter yang mengadopsi cara bercerita film cerita (fiksi) dan ada film cerita (fiksi) yang mengadopsi cara bercerita film dokumenter.

Lebih lanjut dalam ulasan Jurnal Rekam Vol. 14 No. 2 Oktober 2018, Bernard (2007) dalam bukunya Documentary Storytelling, memilikirumusan sejalan dengan pemahamanan itu. Melalui analisis tekstual terhadap proses pembuatan dokumenter, Bernard menghasilkan rumusan yang menyebutkan bahwa dokumenter harus melibatkan berbagai pilihan kreatiftentang struktur film, sudut pandang, keseimbangan, gaya, tokoh, dan lain sebagainya dalam cerita yang disajikan (Bernard, 2007). Bernard dalam perkembangan dokumenter juga berkontribusi dengan merumuskan frasa Documentary Storytelling.

Kontribusi Bernard mengindikasikan perkembangan dokumenter masa kini yang semakin beragam. Bernard menawarkan strategi untuk mencapai kualitas dokumenter melalui cerita dan keterampilan penciptaan narasi unik yang menyampaikan, tidak hanya subjek film saja, tetapi juga tema dan penulisan yang dilakukan secara jujur (Bernard, 2007).

Dan (2012) dalam buku Web TV Series: How To Make and Market Them..(Creative Essentials) menjelaskan dan mengulas langkahlangkah pembuatan tayangan secara serial dan kontinu. Dalam buku ini juga dibahas bagaimana cara memasarkan dengan memediakan karya melalui internet, terutama pada situs YouTube. Selain itu, buku dengan judul Lebih Kreatif dengan YouTube yang ditulis oleh Kukuh Prasetyo ini dijadikan rujukan dalam pola pendistribusian karya secara online melalui web series.

Salah satu referensi karya yang digunakan dalam konteks merangkai cerita dalam perancangan web series dokumenter ini adalah sebuah film dokumenter berjudul Dhaup Ageng produksi Kraton Yogyakarta dan Jiwa Creation Jakarta pada tahun 2011. Film yang menceritakan prosesi pernikahan putra-putri Kraton Yogyakarta ini, secara berurutan dan terperinci mampu mendeskripsikan seluruh rangkaian proses acara pernikahan tersebut. Dengan gaya bertutur secara linier, tanpa adanya narator, rangkaian cerita dibangun melalui testimoni para narasumber. Secara konkret, film ini mampu memberikan sebuah gambaran yang detail mengenai prosesi pernikahan serta memberi informasi baru kepada penontonnya mengenai tata cara pernikahan gaya Kraton Yogyakarta.

Film dokumenter yang berdurasi satu jam lebih ini, secara visual menampilkan adegan wawancara para narasumber dengan ilustrasi visual berdasar pernyataan mereka. Dengan pembagian alur cerita secara tiga babak, 
di antaranya pengenalan, isi, dan penutup, film ini mampu ditonton dan diikuti dengan baik karena pembagian babak ditampilkan secara jelas. Dalam penceritaan model/gaya plot linier seperti ini, kejelasan dalam mengantarkan cerita serta pembagian tiap babak dalam sebuah cerita film dokumenter panjang memang diperlukan. Hal inilah yang memengaruhi berhasil atau tidaknya informasi dalam sebuah film dokumenter tersampaikan kepada penontonnya.

Referensi karya web series yang digunakan ialah Borobudur. Sebuah web series persembahan Pesona Indonesia yang diproduksi oleh Fourcolors Films (2018) sebanyak enam episode ini bercerita tentang mitos dan legenda candi Borobudur. Tujuan dibuatnya web series ini ialah sebagai media edukasi untuk generasi muda agar lebih mengenal sejarah dan cerita di balik kemegahan candi. Tayangan fiksi ilmiah ini sarat akan muatan nilai lokalitas yang terinspirasi dari warga masyarakat desa yang hidup di sekitar situs Candi Borobudur.

\section{METODE PENELITIAN}

Metode/proses pada perancangan web series ini dilakukan secara sistematik. Ada beberapa metode yang dapat digunakan, kesemuanya didasari oleh sebuah tindakan "penelitian" sebagai dasar pijakan dalam proses perancangan web series tersebut. Menurut Soedarsono (1999), observasi cermat terhadap subjek dengan menggabungkan beberapa disiplin ilmu sebagai pendekatan dapat dilakukan dalam sebuah penelitian. Hal ini dilakukan mengingat bahwa proses "penelitian" perancangan web series film dokumenter ini memerlukan beberapa unsur pendekatan yang tidak saja berhenti pada satu disiplin ilmu, tetapi beberapa pendekatan yang sekiranya dapat digunakan untuk mendukung sisi kreativitas dalam proses perancangannya.

Agar terwujud tujuan perancangan web series film dokumenter ini, sangat diperlukan langkah-langkah yang sistematis melalui tahapan pengumpulan data. Secara rinci bisa diamati dari penjelasan mengenai data yang akan dikumpulkan, yaitu: (a) data kepustakaan, berupa buku-buku yang berisi mengenai sejarah kopi di Indonesia, petani kopi, dan industri kopi di wilayah Jawa Tengah dan khususnya di Pengkol, Ngawonggo, Kaliangkrik, Magelang, Jawa Tengah. Literatur lain berupa bukubuku yang berisi topik utama tentang film dokumenter. Buku-buku tersebut secara fisik berujud skrip ataupun yang telah dipublikasikan dalam bentuk e-book portable document file (PDF) yang dapat diunduh melalui internet; (b) data media massa, berupa artikel media massa yang memuat segala ulasan mengenai sejarah kopi di Indonesia, petani kopi, dan industri kopi di wilayah Jawa Tengah dan khususnya di Pengkol, Ngawonggo, Kaliangkrik, Magelang baik yang terbit di surat kabar maupun media on-line di internet; (c) data video dan audio footage, berupa potongan/cukilan arsip audio ataupun visual dalam bentuk foto ataupun video mengenai sejarah kopi di Indonesia, petani kopi, dan industri kopi di wilayah Jawa Tengah dan khususnya di Pengkol, Ngawonggo, Kaliangkrik, Magelang. Data dalam bentuk video dapat diunduh dari situs video YouTube atau pencarian koleksi video dalam bentuk cakram digital atau ekstensi file video yang lain. Data penting yang tidak dapat ditinggalkan adalah berupa wawancara narasumber secara auditif dengan sound recorder ataupun oncamera video; (d) data wawancara, wawancara dilakukan dengan metode insidental sampling dengan narasumber yang berkompeten menurut tema yang telah dipilih. Semua data dari 
wawancara diubah dalam bentuk transkrip sebagai penunjang dalam proses perancangan web series film dokumenter yang berhubungan dengan sejarah kopi di Indonesia, petani kopi, dan industri kopi di wilayah Jawa Tengah dan khususnya di Pengkol, Ngawonggo, Kaliangkrik, Magelang; (e) identifikasi data/ sintesis, setelah data terkumpul, dilakukan identifikasi data, yaitu pengelompokan dan pemilahan berdasar kategori yang sama. Dari beberapa data yang terkumpul dibuatlah analisis dengan cara menghubungkan (sintesis) dari beberapa data yang sama yang berhubungan dengan sejarah kopi di Indonesia, petani kopi, dan industri kopi di wilayah Jawa Tengah dan khususnya di Pengkol, Ngawonggo, Kaliangkrik, Magelang. Data-data ini muncul menjadi variabel-variabel yang akan digunakan sebagai isi (konten naratif) dalam perancangan web series ini. Lebih lanjut seperti dikutip dari Bordwell \& Thompson melalui Lilik Kustanto dkk. dalam artikel Jurnal Rekam Vol. 15 No. 1 April 2019 menyebutkan bagian penting dalam pengumpulan data naratif adalah cerita (story) dan alur cerita (plot). Kedua aspek ini penting dalam memahami suatu narasi, bagaimana narasi bekerja, bagian mana dari suatu peristiwa yang ditampilkan dalam narasi dan bagian mana yang tidak ditampilkan. Di dalam narasi, terdapat dua aspek, yakni: (a) waktu yang terdiri dari elemen; durasi, urutan, dan frekuensi serta (b) ruang.

\section{HASIL DAN PEMBAHASAN}

Berbekal keingintahuan dan semangat berbagi demi kesejahteraan bersama, Rinto memberanikan diri terjun ke dunia kopi setelah mendapat kabar dari salah seorang penyuluh pertanian jika tanaman tembakau suatu saat akan diganti dengan tanaman kopi oleh pemerintah sebagai komoditas pertanian yang ramah lingkungan. Hal ini sepaham dengan prinsip hidup Rinto yang menolak kehadiran asap rokok (tembakau) di rumahnya, walau mayoritas warga desa saat itu sebagian besar adalah petani tembakau yang gemar merokok.

$$
\text { Perjuangan Rinto dan ayahnya }
$$
mengenalkan kopi arabika kepada para petani lain yang mayoritas bertani sayur dan tembakau tidaklah mudah. Banyak yang mencemooh kala itu, tanaman kopi dianggap tidak menjanjikan karena susah dalam pengadaan bibit dan perawatan. Berkat kegigihan sang ayah dan anak, dengan pendekatan kekeluargaan ke Kelompok Tani Mekar Lestari, saling berbagi pengetahuan demi kedaulatan dan kesejahteraan bersama para petani, lambat-laun tanaman kopi mulai dilirik para warga. Terlebih setelah panen perdana, hasil jerih payah para petani kopi yang selama ini hanya dijual di pasar lokal setempat, oleh Rinto dipasarkan ke luar daerah, bahkan hingga ke luar negeri (Turki dan Swedia). Berbagai macam diskusi, pelatihan, dan peningkatan pengetahuan mengenai penanaman serta proses pengolahan kopi ia ikuti. Dengan berbekal biaya sendiri, tanpa bantuan pemerintah lambat laun Rinto mulai menuai hasilnya. Ini dilakukan Rinto karena kebulatan tekadnya untuk menjadikan kopi arabika jawa kembali ke pasar dunia (road to specialty coffee).

Perkembangan multimedia pada masa sekarang ini memiliki peran yang sangat besar dalam bidang komunikasi, informasi, bisnis, pendidikan, dan perindustrian karena multimedia dapat menggabungkan teks, grafik, animasi, audio, dan video. Seiring dengan kemajuan teknologi, pemunculan tayangan film dokumenter seri ini nantinya tidak hanya sebatas di bidang layar televisi, tetapi 
juga merambah dunia maya dengan revolusi teknologi informasi yang dilakukan oleh situs YouTube.

Siapa pun dapat memancarkan (membraodcasting-kan) tayangan dalam bentuk video, termasuk film. Dengan meminjam genre tersebut, agar karya film dokumenter ini dapat disebarluaskan kepada publik, media presentasi yang dipilih adalah YouTube. Situs ini telah menciptakan era baru dalam hal media pendistribusian, penyimpanan, dan pendokumentasian sebuah video, tidak terkecuali film. Dengan data video digital yang diunggah, akses khalayak terhadap karya film dokumenter ini akan semakin mudah dan terbuka. Hal ini bertujuan agar file video yang diunggah dapat diapresiasi secara terbuka oleh masyarakat umum, salah satunya adalah web series.

Web series adalah serial video online yang didistribusikan melalui internet. Kekhasan dari web series adalah para konten kreator membuat sebuah tayangan yang konsisten dan berkesinambungan serta membangun interaktivitas dari komunitasnya, yaitu para penonton rutin. Beberapa faktor mengapa web series muncul adalah pertama, sebagian besar pengguna internet menonton konten video, dan jumlah ratarata dilihat terus meningkat...Alasan lain adalah menjadi adanya website seperti Youtube memungkinkan pengguna dari seluruh dunia untuk mengunggah dan berbagi kreasi mereka sendiri (Dan, 2012).

Kisah Rinto dan sang ayah dapat dijadikan contoh betapa kebulatan tekad dan perjuangan memajukan para petani kopi menuju kemandirian serta kedaulatan ekonomi dapat disaksikan melalui film dokumenter dalam bentuk web series ini sebagai media revitalisasi kopi jawa menuju desa berdaya melalui potensi masyarakat desa di Jawa Tengah.
Web series film dokumenter ini bercerita tentang perjuangan keluarga Sasongko melalui Kelompok Tani Mekar Lestari Kaliangkrik dalam membudidayakan kopi arabika di desanya serta bagaimana mereka mempertahankan dan meyakinkan para petani kopi untuk tetap bertahan hingga saat ini. Di samping itu, perjuangan dan idealisme Rinto dalam usahanya untuk belajar dan memahami kopi hingga saat ini menjadikan kopi kaliangkrik cukup dikenal oleh para pencinta kopi akhir-akhir ini. Dia berharap kopi kaliangkrik bisa diakui dan layak menyandang kopi specialty. Sudut pandang penceritaan dalam web series dokumenter ini melalui sosok Sasongko sebagai representasi jiwa dan semangat petani kopi konvensional. Sementara itu, sosok Rinto adalah sebagai representasi idealisme generasi modern petani kopi.

Porsi dan bobot penceritaan terbagi menjadi dua bagian. Dalam episode pertama bercerita mengenai keluarga Sasongko dalam mempertahankan tanaman kopi (istiqomah terhadap kopi) dan pada episode kedua bercerita mengenai sosok Rinto yang berperan besar sebagai “penghubung” antara Kelompok Tani Mekar Lestari dan para pecinta kopi. Lebih lanjut, dapat dijabarkan dalam sinopsis cerita: (a) episode pertama: Kabupaten Magelang terkenal sebagai daerah yang beriklim sejuk dengan hamparan tanah pegunungan yang subur. Sayur mayur, buah-buahan, dan bunga merupakan hasil bumi yang sangat populer di kalangan masyarakat dan petani. Akan tetapi, lain cerita dengan kopi. Ya, kopi. Kopi jenis arabika pula! Tidak banyak orang tahu (bahkan pencinta dan pelaku usaha kopi) kalau di kaki Gunung Sumbing tepatnya di Ngawonggo, Kaliangkrik terdapat kopi berkualitas enak. Adalah Kelompok Tani Mekar 
Lestari yang menjadi saksi perjuangan dalam mempertahankan ideologi mereka dengan "beristiqomah" terhadap kopi hingga akhirnya mampu menemukan ceruk pasar industri kopi dari hulu hingga hilir saat ini. Sayangnya, semangat mereka hampir pupus ketika dahulu harapan besar terhadap kopi sirna akibat ulah para tengkulak pengijon kopi. Mereka meninggalkan cerita "pahit" ketika kopi-kopi hasil panen para petani tidak dibeli karena tidak mencukupi dari sisi kuantitas. Mereka enggan membeli. Panen kopi menumpuk, bingung mau dijual ke mana. Berkat peran Sasongko dan Rinto, berkat kerja keras keduanya dan didukung semangat saling berbagi untuk menguatkan kelompok tani serta rasa syukur mereka terhadap alam, mereka bertekad untuk memasarkan dan mengembangkan kopi kaliangkrik ini secara mandiri. Menjadi petani kopi yang berdaulat dan berwawasan modern sebagai closing statement film tentang ideologi petani yang "istiqomah" terhadap kopi; (b) episode kedua: harapan besar tentang kopi itu pun datang kembali. Sebutlah Komunitas Kopi Magelang yang kali pertama "menemukan" kopi mereka ini. Berkat usaha dan keuletan Rinto dalam mengenalkan dan memasarkan kopinya, akhirnya sekelompok anak muda ini dengan penuh semangat mau memberikan edukasi kepada para petani kopi tentang bagaimana cara memperlakukan kopi dengan semestinya hingga menjadi kopi berkualitas baik dan enak. Keharusan kopi petik merah hingga pengetahuan proses pengolahan kopi pascapanen mereka bagikan dan ajarkan. Uniknya, untuk meyakinkan para petani kopi Mekar Lestari, mereka memproses kopi hingga siap seduh dan diminum oleh anggota kelompok tani. Terjadi dialetika di antara mereka bagaimana cara menilai dan menghargai kualitas secangkir kopi, terlebih kopi mereka sendiri. Semangat saling berbagi hadir di sini.

Sasongko dan Rinto sebagai motor penggerak dalam usaha percontohan pengolahan kopi pascapanen ini dengan penuh rasa keikhlasan dan ketulusan melibatkan semua anggota keluarganya, dari proses pemetikan buah kopi, penjemuran buah kopi, pemrosesan pascapanen, hingga penyortiran biji kopi. Hal ini menunjukkan kerja keras dan keuletan sebagai petani kopi sangat diperlukan sehingga harapannya dapat dicontoh oleh anggota Kelompok Tani Mekar Lestari lainnya. Dari sinilah tercipta biji kopi kaliangkrik dengan standar kualitas kafe yang siap dipasarkan ke kedai kopi atau coffee shop.
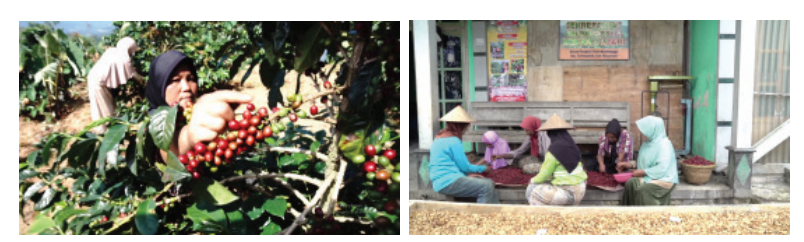

Gambar 1 Aktivitas Kelompok Tani

Mekar Lestari dalam Mengolah Kopi

(Sumber : Web Series Kopi Kaliangkrik Road to Specialty, 2019)
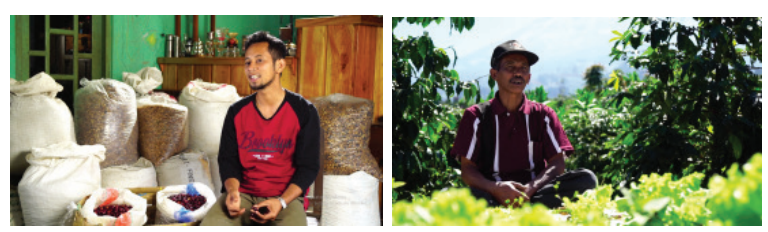

Gambar 2 Wawancara Narasumber Rinto dan Sasongko

(Sumber: Web Series Kopi Kaliangkrik Road to Specialty, 2019)

Kehadiran Kedai Coffeetography, AyGo, dan Darat Coffee Lab merupakan "pengakuan" bagi kopi kaliangkrik sebagai kopi dengan cita rasa "spesial". Akan tetapi, tidak hanya berhenti pada ini saja, kopi kaliangkrik "butuh" 
pengakuan dari para Q-Grader Coffee untuk dapat melanjutkan langkahnya menuju kopi "kelas dunia". Rinto sebagai petani kopi dengan wawasan yang visioner berusaha mewujudkan hal ini sebagai wujud rasa terima kasihnya terhadap kopi yang telah menghidupi.

\section{SIMPULAN}

Hal pokok yang menarik dan penting dalam perancangan web series film dokumenter seri ini adalah bahwa potensi-potensi yang dimiliki oleh masyarakat desa yang selama ini jarang diekspos dapat disampaikan dan disebarluaskan kepada publik atau khalayak melalui sebuah karya film dokumenter seri yang dapat diakses secara terbuka melalui YouTube.

Melalui perancangan web series ini pula, langkah nyata dalam mengupayakan dan mewujudkan harapan serta tujuan percepatan akses keterbukaan informasi pedesaan dapat dilakukan guna mengakselerasi potensi sumber daya alam dan sumber daya manusia, khususnya petani kopi di Pengkol, Ngawonggo, Kaliangkrik, Magelang, Jawa Tengah sebagai salah satu upaya revitalisasi di bidang pertanian melalui medium film dokumenter.

\section{KEPUSTAKAAN}

\section{Buku:}

Dan, W. (2012). Web TV Series: How To Make and Market Them..(Creative Essentials). London.

Fred Wibowo. (1997). Dasar-Dasar Produksi Program Televisi. Jakarta: Grasindo.

Indarto Prawoto. (2013). The Road to Java Coffee. Jakarta: Penerbit Specialty Coffee Asociation of Indonesia.

Rabiger, M.(1992).Directing The Documentary. Boston: Focal Press.
Rosenthal, A. (1990). Writing, Directing, Producing Documentary Films and Videos (Revised Editions. Boston: Southern Ilinois University Press.

Soedarsono, R. . (1999). Metodologi Penelitian Seni Pertunjukan dan Seni Rupa. Bandung: Masyarakat Seni Pertunjukan Indonesia.

Subroto, D. S. (1994). Produksi Acara Televisi. Yogyakarta: Duta Wacana University Press.

Ukers, W. (1922). All About Coffee. New York: New York The Tea and Coffee Trade Journal Co.

Wurtzel, A., \& Acker R, S. (1983). Television Production (Third Edition) (Third). Michigan: McGraw-Hill.

\section{Jurnal:}

Laurensia Irma Saraswati, Prototipe Web Series Untung si Bejo, Fakultas Ilmu Sosial dan Politik Universitas Indonesia, 2014.

Lilik Kustanto, Rr. Ariprasetyowati, Ozhara Aisyia, Konstruksi Keistimewaan Yogyakarta dalam Narasi Film-film Kompetisi Produksi Dinas Kebudayaan Yogyakarta 2016-2017, Jurnal Rekam Vo. 15 No.1 April 2019 (hal. 49-59)

Renta Vulkanita Hasan, G.R Lono Lastoro Simatupang, Kurniawan Adi Saputro, Problem dan Alaternatif Sudut Pandang Terhadap Klaim Filmis Kebenaran Film Dokumenter, Jurnal Rekam Vo. 14 No. 2 Oktober 2018 (hal. 77-86)

\section{Pustaka Laman:}

https://www.youtube.com/channel/UCaqfclByQfpiq7fqfoDg9w, diakses pada hari Senin 8 April 2019 pukul 19.00 WIB. 
https://www.youtube.com/watch?v=rmezPTh-

5wI1, diakses pada hari Senin 1 April 2019 pukul 19.00 WIB.

ht tps://www.youtube.com/ watch? $v=z T$ tpFmgBmTI, diakses pada hari Senin, 1 April 2019 pukul 19.10 WIB.

google image, diakses pada hari Selasa, 4 Juli 2017 pukul 05.50 WIB.

\section{Filmografi:}

Film Dokumenter Dhaup Ageng Kraton

Yogyakarta, Jiwa Creation, 2011.

Web Series Borobudur, Fourcolors Films, 2018.

\section{Narasumber:}

Surip Mawardi, Pusat Penelitian Kopi dan Kakao Indonesia, 26 Juli 2015, pukul 09.00 WIB di Kota Jember (wawancara dilakukan dalam rangka pembuatan karya dokumenter Road Trip A Cup of Java-Bloomberg TV 2015).

Rinto, Petani Kopi Kelompok Mekar Lestari, 31 Maret 2019 di Dusun Pengkol, Desa Ngawonggo, Kecamatan Kaliangkrik, Kabupaten Magelang, Jawa Tengah, pukul 10.30 WIB.

Chaesary Husna Rekinagara, Komunitas Kopi Magelang (KKM), 26 Mei 2019 di Kedai Coffeetography, pukul 21.00 WIB.

Dewan, Komunitas Kopi Magelang (KKM), 22 September 2019 di Serangkai Kopi, pukul 20.00 WIB. 